\title{
Unilateral eyelid, conjunctival, and choroidal tumours as initial presentation of diffuse large-cell lymphoma
}

\author{
STEVEN R LEFF,' JERRY A SHIELDS,' JAMES J AUGSBURGER,' \\ ROBERT V MILLER, ${ }^{2}$ AND BENJAMIN LIBERATORE ${ }^{2}$
}

From the 'Oncology Service, Wills Eye Hospital, Jefferson Medical College, Thomas Jefferson University, Philadelphia, PA, and ${ }^{2}$ Newcomb Hospital, Vineland, NJ, USA

SUMmARY Simultaneous ipsilateral eyelid, conjunctival, and choroidal tumours developed in an otherwise healthy man. Biopsy of the eyelid mass led to the diagnosis of large-cell lymphoma. Further examination revealed systemic lymphoma. Although the ocular and adnexal lesions responded to systemic chemotherapy, additional skin tumours later developed. Large-cell lymphoma (also called reticulum cell sarcoma and histiocytic lymphoma) is becoming increasingly recognised for its ophthalmic manifestations. The clinical signs, diagnostic investigations, and treatment of this disease are discussed.

Large-cell lymphoma (also known as reticulum cell sarcoma and histiocytic lymphoma) has recently gained considerable attention in the ophthalmic literature. It is the lymphoma with the greatest frequency of ocular involvement. There are basically two forms of this malignancy. The first type, with frequent intraocular involvement, is likely to present as a persistent uveitis. ' It is usually associated with central nervous system (CNS) tumour and no systemic disease. However, the more common type of large-cell lymphoma is the diffuse systemic form. Although ocular adnexal and orbital involvement is often reported, intraocular manifestations are considerably less frequent.

It is well documented that patients with systemic lymphoma may present initially with eyelid involvement. ${ }^{23}$ However, we were unable to find any reports of both intraocular and adnexal tumour together preceding systemic signs. This paper describes a patient who we believe is the first to present initially with simultaneous eyelid, conjunctival, and choroidal large-cell lymphoma before systemic disease was obvious.

\section{Case report}

In September 1983, an 80-year-old previously healthy white man was referred to the Oncology

Correspondence to Dr S R Leff, Oncology Service, Wills Eye Hospital, Ninth and Walnut Streets, Philadelphia, PA 19107, USA.
Service of Wills Eye Hospital. His past ocular history was negative except for uncomplicated intracapsular cataract extractions in 1959 and 1975 in the left and right eyes respectively, and ocular-sparing left facial herpes zoster in 1971. His family history was unremarkable.

Eight weeks prior to our consultation he had noted slight tearing from his left eye. The patient's ophthalmologist noted a mass in the left brow and several ipsilateral fundus lesions. Metastatic carcinoma was suspected, and a laboratory and radiological survey was ordered. However, chest $x$-ray, complete blood count, blood chemistry tests,

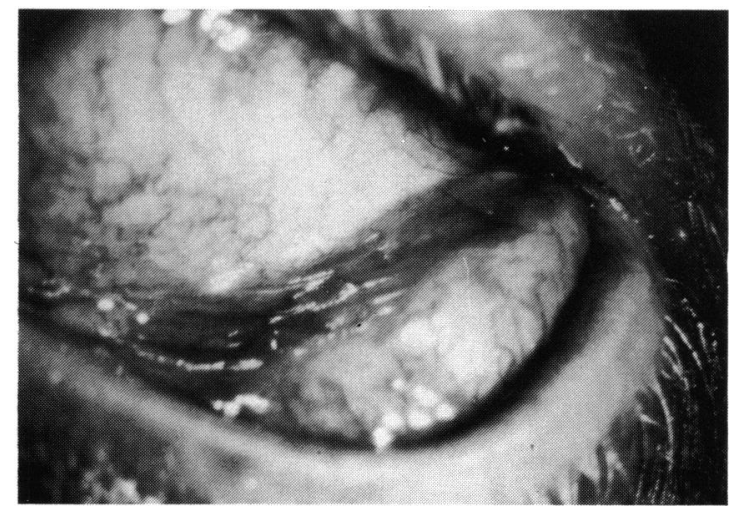

Fig. 1 Clinical photograph of left lower eyelid and conjunctiva demonstrating the area of tumour. 


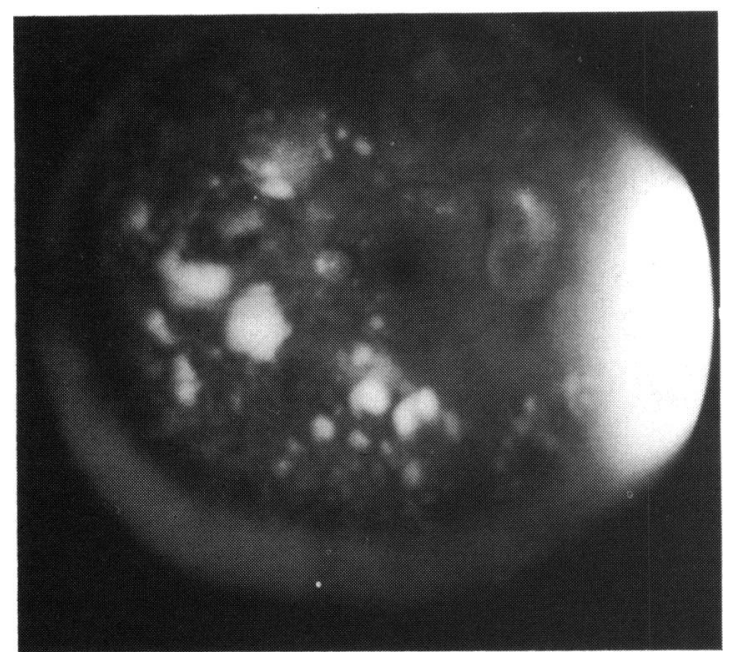

Fig. 2 Wide angle fundus photograph of choroidal tumours in the left eye. There is an incidental temporal island of chorioretinal atrophy.

and computed tomography (CT) scan of head and body were all negative.

When first seen at our service the patient's best corrected visual acuity was $6 / 5$ in the right eye and $6 / 9$ in the left. A firm, non-tender, $3 \times 2 \mathrm{~cm}$ nodule was palpable beneath the left brow. A similar lesion measuring $1 \times 1 \mathrm{~cm}$ involved the left palpebral and bulbar conjunctiva inferolaterally (Fig. 1). The intra- ocular pressure was $17 \mathrm{mmHg}$ in the right eye and 11 in the left.

Biomicroscopy revealed normal anterior segments and aphakia in each eye. Vitreoretinal examination was normal in the right eye. In the left eye, however, multiple, slightly elevated yellow choroidal tumours ranging from 1 to $6 \mathrm{~mm}$ in diameter were present in the posterior pole and pre-equatorial regions (Fig. 2). There was shallow subretinal fluid overlying some of the larger lesions. The optic disc was normal and the vitreous was clear. A preoperative physical examination gave normal findings except for slight cervical and inguinal lymphadenopathy.

It was decided to biopsy the large brow mass. At surgery an unencapsulated, grey tumour was encountered and a wedge biopsy specimen taken. Histological examination showed a tumour composed predominantly of rather uniform large lymphocytes, which diffusely infiltrated the soft adipose tissues and surrounding nerves and blood vessels (Fig. 3). The nuclei were clear. From the nucleoli, which were large and irregularly shaped, emanated chromatin strands, which condensed along the nuclear rim. There were scattered benign lymphocytes as well. The pathological diagnosis was large-cell lymphoma.

Further systemic examination revealed no additional evidence of lymphoma. Cyclic combination chemotherapy with cyclophosphamide, adriamycin, vincristine, and prednisone was begun, and all
Fig. 3 Photomicrograph of left brow biopsy specimen. Note lymphoid cells infiltrating normal tissue (Haematoxylin-eosin, $\times 250$ ).

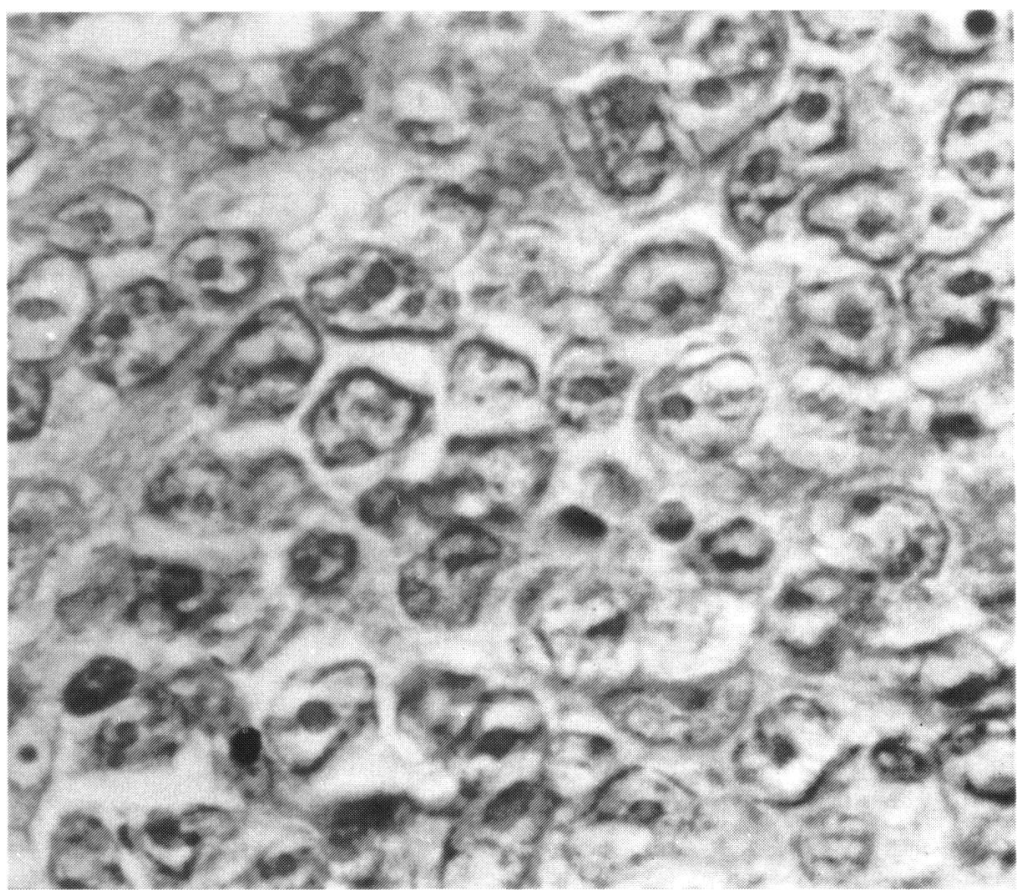




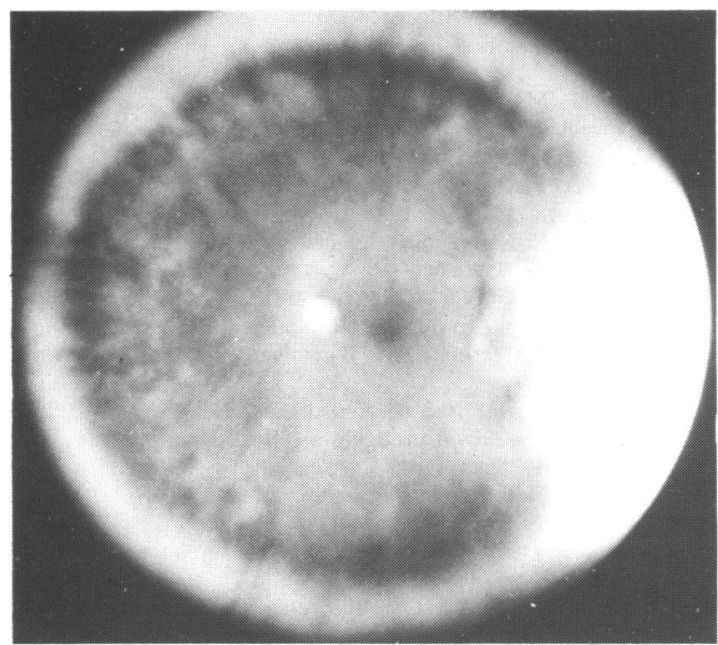

Fig. 4 Post-treatment wide angle photograph of the left fundus. Note regression of tumours.

known lesions including the lymphadenopathy regressed dramatically (Fig. 4). The visual acuity in the left eye improved to $6 / 5$.

Six months later and only several weeks after the patient's sixth cycle of chemotherapy a new subcutaneous mass developed in the left breast. A slight swelling in the area of the right brow was also evident. A biopsy of the breast lesion was performed and a firm, walnut-sized nodule was removed. At microscopic examination a tumour composed of monomorphic lymphoid cells infiltrating the normal fat and connective tissue of the breast was identified. A review of the slides from the previous lid specimen showed the lesions to be histologically similar. The breast as well as the brow tumour also resolved on further chemotherapy. However, the patient returned in August 1984 with a $1 \times 1 \mathrm{~cm}$ right lower lid nodule (Fig. 5). Additional chemotherapy is being undertaken.

\section{Discussion}

Large-cell lymphoma can be divided into two main presentation patterns. The first and most important to ophthalmologists is the intraocular-central nervous system (CNS) type. The combination of these two sites together $75 \%$ of the time clearly labels this as a distinct entity. There is only a $25 \%$ association with disseminated large cell lymphoma in this form. ${ }^{4}$ Usually eye findings precede CNS clinical signs by an average of 21 months. ${ }^{56}$ However, CNS disease rarely occurs before eye involvement. A posterior uveitis or a vitritis with or without chorioretinal involvement is the main feature. ${ }^{78}$

Diffuse systemic large-cell lymphoma is far commoner than the ocular-CNS form. Mainly a disease of lymph nodes, spleen, and bone marrow, it can also begin in the viscera or skin. This form is not usually associated with ophthalmic disease. However, when it occurs, orbital or ocular adnexal involvements is far more likely to be seen than intraocular lesions. ${ }^{910}$ In addition, intraocular involvement here is more likely to be choroidal, as opposed to retinal or vitreal, as usually seen in the ocular-CNS form. ${ }^{11}$ Proptosis and periorbital swelling are the typical presenting adnexal manifestations. ${ }^{12}$

Recent immunofluorescent techniques have detected immunoglobulins on the surface of the cells. ${ }^{12-15}$ It now appears that large-cell lymphomas are derived mostly from B lymphocytes and rarely from T lymphocytes.

Our patient with systemic lymphoma is unusual in several respects. He represents one of the few cases

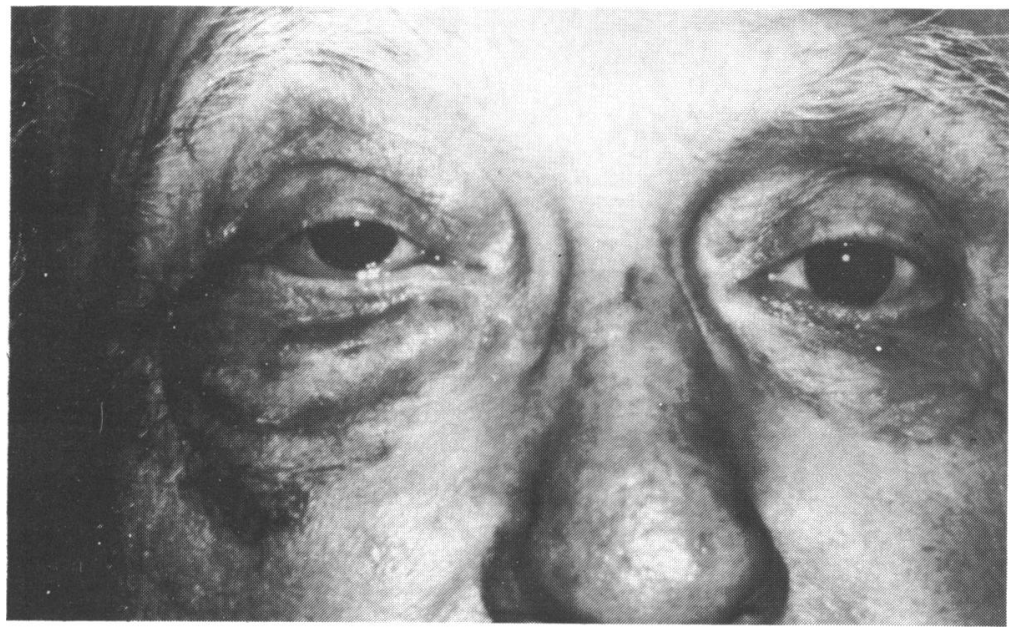

Fig. 5 Clinical photograph of right lower lid nodule. 
of intraocular disease presenting in the systemic form of the malignancy. He is even more unusual in that his choroidal tumours became manifest early in the course of his illness and before any systemic signs or symptoms occurred. In addition he also had eyelid and conjunctival tumours, which prompted him to seek medical attention. The fact that his initial intraocular and periocular lesions were ipsilateral rather than contralateral may be coincidental, but the ocular-CNS form of large-cell lymphoma does tend to be ipsilateral. ${ }^{16}$ However, it is also curious that our patient's later tumour sites involved the right periorbita.

Chemotherapy was used to good advantage in our patient. Both the original ophthalmic tumours as well as the later recurrences responded dramatically. Any future site will be similarly treated, with local radiotherapy held in reserve. Unfortunately there is no curative treatment for large-cell lymphoma, and the prognosis for our patient remains guarded.

This work was supported in part by the Ocular Oncology Fund, Wills Eye Hospital, the Oncology Research Fund, Wills Eye Hospital, and in part by the Pennsylvania Lions Sight Conservation and Eye Research Foundation, Inc.

\section{References}

1 Barr CC, Green WR, Payne JW, Knox DL, Jensen AO, Thompson RL. Intraocular reticulum cell sarcoma. Clinicopathologic study of four cases and review of the literature. Surv Ophthalmol 1975; 19: 224-39.

2 Shields JA. Malignant lymphoma presenting as a unilateral eyelid mass. Ann Ophthalmol 1975; 7: 1689-91.
3 Jakobiec FA, Gibralter RA, Knowles OM, Iwamoto T. Lymphoid tumours of the lid. Ophthalmology (Rochester) 1980; 85: $1058-64$.

4 Char DH, Margolis L, Newman AB. Ocular reticulum cell sarcoma. Am J Ophthalmol 1981; 91: 480-3.

5 Sloas HA, Starling J, Harper DG, Cupples HP. Update of ocular reticulum cell sarcoma. Arch Ophthalmol 1981; 99: 1048-52.

6 Rosenbaum TJ, MacCarty CS, Buettner H. Uveitis and cerebral reticulum cell sarcoma (large-cell lymphoma): case report. J Neurosurg 1979; 50: 660-4.

7 Minckler DS, Font RL, Zimmerman LE. Uveitis and reticulum cell sarcoma of the brain with bilateral neoplastic seeding of the vitreous without retinal or uveal involvement. Am J Ophthalmol 1975; 80: 433-9.

8 Kennerdell JS, Johnson BL, Wisotzkey HM. Vitreous cellular reaction associated with reticulum cell sarcoma of brain. Arch Ophthalmol 1975; 93: 1341-5.

9 Collyer R. Reticulum cell sarcoma of eye and orbit. Can J Ophthalmol 1972; 7: 247-9.

10 Currey TA, Deutsch AR. Reticulum cell sarcoma of the uvea. South Med J 1965; 58: 919-22.

11 Klingele TG, Hogan MJ. Ocular reticulum cell sarcoma. Am J Ophthalmol 1975; 79: 39-48.

12 Jakobiec FA, Williams P, Wolff M. Reticulum cell sarcoma (histiocytic lymphoma) of the orbit. Surv Ophthalmol 1978; 22: 255-69.

13 Kaplan H, Meredith TA, Aaberg TM, Keller RH. Reclassification of intraocular reticulum cell sarcoma (histiocytic lymphoma): immunologic characteristics of vitreous cells. Arch Ophthalmol 1980; 89: 707-10.

14 Saga T, Ohno S, Matsuda H, Ogaswara M, Kikuchi K. Ocular involvement by a peripheral T-cell lymphoma. Arch Ophthalmol 1984; 102: 399-402.

15 Michelson JB, Michelson PE, Bordin GM, Chisari FV. Ocular reticulum cell sarcoma: presentation as retinal detachment with demonstration of monoclonal immunoglobulin light chains on the vitreous cells. Arch Ophthalmol 1981; 99: 1409-11.

16 Qualman SJ, Mendelsohn G, Mann RB, Green WR. Intraocular lymphoma. Natural history based on clinico-pathologic study of 8 cases and review of the literature. Cancer 1983; 52 878-86. 